\title{
Thermophysical and Absorption Properties of Brominated Vegetable Oil
}

Matthew J. Thomas, ${ }^{\dagger}$ Katlyn A. Bramblett, Blane D. Green, Kevin N. West ${ }^{*}$

Department of Chemical \& Biomolecular Engineering, University of South Alabama, Mobile,

AL 36688 (USA)

\section{Corresponding Author}

*Dr. Kevin N. West, Associate Professor, Department of Chemical \& Biomolecular Engineering University of South Alabama, Mobile, AL 36688

kevinwest@southalabama.edu, 251.460.7563

${ }^{\dagger}$ Current address: Phillips Alliance Refinery, Belle Chase LA, 70037 


\title{
ABSTRACT
}

Brominated vegetable oil (BVO) is a dense, bio-derived food additive used to emulsify citrus flavors in a variety of manufactured beverages. Although its high density is well known, accurate values for density and other properties, such as melting point, viscosity, refractive index and liquid phase heat capacity are not available in the literature. In this work, these properties are measured and correlated as a function of temperature from $\sim 273 \mathrm{~K}$ to $\sim 353 \mathrm{~K}$. The volume expansivity, derived from the density, is also calculated. The density, viscosity and heat capacity are then compared with corresponding literature values for natural, unmodified oils. While the density and viscosity are markedly higher than the natural oils, the heat capacity is not significantly different. Through comparison with the viscosities of halogenated internal alkenes, it is shown that the increase in viscosity is likely due to enhanced dispersion forces, rather than enhanced polarity upon bromination. Additionally, the solubility of $\mathrm{N}_{2} \mathrm{O}$ and $\mathrm{CO}_{2}$ in brominated vegetable oil are measured at $310 \mathrm{~K}$ from $0.01 \mathrm{MPa}$ to $2 \mathrm{MPa}$ and, like unmodified olive oil, brominated vegetable oil exhibits higher $\mathrm{N}_{2} \mathrm{O}$ solubility than $\mathrm{CO}_{2}$ solubility. Such property trends are expected to be predictive of trends encountered when recently described lipidic ionic liquids are compared with their brominated analogues.

\section{Keywords}

natural oils, halogenated triacylglycerols, thermophysical properties

\author{
Abbreviations \\ BVO - Brominated Vegetable oil
}




\section{Introduction}

Brominated vegetable oil (BVO), synthesized by reacting $\mathrm{Br}_{2}$ with soybean oil, has been used as an additive in the beverage industry since the early 1930s.[1] The addition of bromine across the double bond has two known significant effects on the physical properties of the oil. First, like hydrogenation, the addition of the bromine atoms results in a saturated triacylglycerol which is much less prone to oxidative degradation than the unsaturated oil; however, unlike hydrogenation, the resulting saturated oil remains a liquid. Second, the addition of the massive bromine atoms significantly increases the density of the oil, from $\sim 0.9 \mathrm{~g} / \mathrm{cm}^{3}$ to $\sim 1.3 \mathrm{~g} / \mathrm{cm}^{3}$. It is the latter property, enhanced density, which has been exploited by the beverage industry.

By adding small amounts ( $~ 8 \mathrm{ppm}$ of total solution) of BVO to citrus flavor compounds, which are sparingly soluble in water, the density of the non-polar phase can be increased to approximate that of water, or more often, water containing sugars that make up the bulk of the beverage. The resulting emulsion is kinetically stable and remains so for the practical shelf life of the product. The safety of BVO as a food additive has been questioned for several decades, [1, 2] though its use has continued. Although still approved for use in the U.S. and Canada, recent consumer led efforts[3] have resulted in decisions to remove BVO from popular beverages in the near future in favor of substitutes such as glycerol ester of wood rosin and sucrose acetate isobutyrate.[4] In addition to its use as a beverage additive, BVO has been examined as a potential flame retardant additive for consumer products.[5]

Our interest in BVO stems from our work developing lipidic ionic liquids, or ionic liquids with considerable non-polar content. Lipidic ionic liquids are designed to have higher solubilities for non-polar species than do traditional ionic liquids, which are polar to moderately polar in nature. The first generation of lipidic ionic liquids we described were 1-methyl-3- $n$-alkylimidazolium 
bistriflimide salts where the alkyl chain contained 16-20 carbons with one or more double bonds.[6] Long alkyl chains were added to the imidazolium cation to increase its nonpolar character; however, it is known that adding saturated alkyl chains longer than 9 carbons results in melting point increasing with chain length.[7-11] Inspired by natural lipids, and using starting materials derived from them, we included unsaturations in the alkyl side chain and, as with unsaturated lipids compared with saturated lipids, we observed a significant decrease in melting point: a $\Delta \mathrm{T}_{\mathrm{m}}$ of $\sim 75^{\circ} \mathrm{C}$ when a cis-9,10 double bond is introduced into a $\mathrm{C}_{18}$ alkyl side chain of the cation.[6] The melting point depression was observed for both cis and trans double bonds, but the effect was more pronounced for cis unsaturations, presumably due to a greater decrease in packing efficiency when the "kinked" cis bond was present. Additional structural moieties, such as cyclopropyl rings added mid-chain,[12] were also observed to lower melting points relative to saturated $n$-alkyl chains and commercially available cationic lipids used for liposome formation and gene delivery were observed to collapse into ionic liquids when hydrophilic anions $\left(\mathrm{Cl}^{-}, \mathrm{Br}^{-}\right)$were replaced with bistriflimide.[13] Recently, we have shown that the inclusion of a sulfur atom, rather than an unsaturation, in the side chain (resulting in 1-thiaalkyl3-methylimidazolium bistriflimide salts) produces similar melting point depression without the possibility of oxidative cleavage of double bonds.[14] Notably, the position of the sulfur in the chain has a strong effect on the melting point depression in a fashion similar to that of molecular thioethers.

Bromination of the double bond in a lipidic ionic liquid side chain, in a manner similar to the synthesis of BVO, may also yield ionic liquids with large non-polar domains, low melting points and even greater thermal stability. Before endeavoring to synthesize such species, we wished to compare the thermophysical properties of BVO to those of vegetable oil to gain an understanding 
of how bromination may affect the properties of the lipidic ionic liquids. However, little information about the thermophysical properties of BVO is available in the literature, prompting this study. We have measured the mixture melting point, density, viscosity, refractive index and liquid phase heat capacity of a sample of commercially available BVO and compare several of these properties to those of natural, unmodified oils.

Additionally, unmodified natural oils, such as olive oil, are known to have higher $\mathrm{N}_{2} \mathrm{O}$ solubility than $\mathrm{CO}_{2}$ solubility, a property that is linked to the ability of $\mathrm{N}_{2} \mathrm{O}$ to act as an anesthetic, while $\mathrm{CO}_{2}$ has negligible anesthetic properties under the same conditions, as the biological activity of such anesthetics is tied to their ability to dissolve in a lipid bilayer. Recently, the authors have demonstrated that a significant differential solubility between these gases exists in lipid ionic liquids,[15] even though the solubilities of the two gases are almost identical in shorter chain, conventional ionic liquids.[16] Here we have investigated the solubility of these gases in BVO to determine if this differential solubility persists in the brominated versions of natural oils.

\section{Experimental}

\subsection{Materials}

Brominated vegetable oil (Table 1) was donated by American Chemical Service, Inc. (ACS). The supplied material was $99 \%$ brominated soybean oil with $1 \%$ being epoxidized soybean oil. The nominal molar mass reported by the manufacturer was $1090 \mathrm{~g} / \mathrm{mol}$. The free fatty acid percent (as \% oleic) was reported as 0.11 using AOCS Ca 5a-40 and iodine value was 3.09 as measured by AOCS Cd 1-25. 
Table 1. Sample description table.

\begin{tabular}{|c|c|c|c|}
\hline $\begin{array}{l}\text { Chemical } \\
\text { Name }\end{array}$ & Source & Initial Mole & Purification \\
\hline
\end{tabular}

Brominated Vegetable Oil

American Chemical

0.99

none (mixture of brominated

Service, Inc. triacylglycerols)

\subsection{Melting Point}

The melting point of the BVO sample, which is a mixture of brominated triacylglycerols of differing chain lengths and degrees of unsaturation, was measured using a TA Instruments Q2000 Differential Scanning Calorimeter with samples of 5-25 mg. Samples were run in open pans under nitrogen and pretreated at $100^{\circ} \mathrm{C}$ for at least 10 minutes to remove volatile contaminants. Additional thermal pretreatments to promote more uniform transition to the isotropic liquid phase are described below.

\subsection{Density}

Density measurements were made using an Anton Paar DSA 5000 vibrating tube densitometer. The densities of the BVO were measured in the temperature range from $273.15 \mathrm{~K}$ to $343.14 \mathrm{~K}$ $( \pm 0.01 \mathrm{~K})$. The densitometer was calibrated with Millipore quality water prior to and during measurements, with no detectible drift in accuracy. The reported values are the average of three trials with the standard uncertainty calculated as the standard deviation of the mean.

\subsection{Dynamic Viscosity}

Dynamic viscosity measurements were made using an Anton Paar AMVn microviscometer equipped with $1.6,1.8,3.0$ and $4.0 \mathrm{~mm}$ glass capillary tubes, for varying viscosity ranges, using 
the rolling ball method. The steel ball and sample were loaded into the capillary tubes using the filling caps provided by the instrument manufacturer, ensuring no air bubbles were present in the tubes. The capillaries were then inserted into the temperature controlled rotor arm of the AMVn and allowed to come to thermal equilibrium. After the trials were completed, the temperature was changed and the process repeated. For each temperature at least 40 trials (rolls of the ball) were recorded. The viscosity of BVO was measured in the temperature range from $305.65 \mathrm{~K}$ to $363.15 \mathrm{~K}( \pm 0.01 \mathrm{~K})$. The viscosity was calculated using eq. 1 , where $k_{c}$ is the capillary tube constant, $t_{r}$ is the roll time, $\rho$ ball is the ball density and $\rho$ fluid is the fluid density.

$$
\eta(m P a \cdot s)=k_{c} t_{r}\left(\rho_{\text {ball }}-\rho_{\text {fluid }}\right)
$$

The reported values are the average of the 40 trials with the reported standard uncertainty calculated as the standard deviation of the mean.

\subsection{Refractive Index}

Indices of refraction were measured on a ThermoFisher Scientific Abbe Refractometer in the temperature range $273.15 \mathrm{~K}$ to $353.15 \mathrm{~K}( \pm 0.1 \mathrm{~K})$. At each temperature the instrument was calibrated using standards from Cargille Laboratories $\left(n_{D}=1.4600,1.5000,1.5200\right)$ and measurements were reproducible to within \pm 0.0005 . The reported values are the average of three trials with the standard uncertainty calculated as the standard deviation of the mean.

\subsection{Heat Capacity: Differential Scanning Calorimeter}

Liquid phase heat capacities were measured from 278.15 to $408.15 \mathrm{~K}$ using a TA Instruments Q2000 Differential Scanning Calorimeter with samples of 5-15 mg. Samples were run in open pans under nitrogen and pretreated at $100^{\circ} \mathrm{C}$ for at least 10 minutes to remove volatile 
contaminants. Data was exported for analysis at $10 \mathrm{~K}$ intervals and the data reported is the average of three trials with the standard uncertainty calculated as the standard deviation of the mean.

\subsection{Solubility of $\mathrm{CO}_{2}$ and $\mathrm{N}_{2} \mathrm{O}$ in $\mathrm{BVO}$}

Solubility measurements were made using a Hiden Isochema Intelligent Gravimetric Analyzer (IGA). The IGA utilizes a microbalance housed in a temperature and pressure controlled environment to expose a sample of solid or nonvolatile liquid to a gas or vapor stream while monitoring uptake of gas/vapor gravimetrically. The temperature is controlled accurately to within $\pm 0.1 \mathrm{~K}$ and the pressure to within $\pm 0.8 \mathrm{kPa}$. For these measurements, the IGA was used in static mode with intermittent gas flow to maintain a constant partial pressure of $\mathrm{CO}_{2}$ or $\mathrm{N}_{2} \mathrm{O}$. Measurements were taken at $310 \mathrm{~K}\left(37^{\circ} \mathrm{C}\right.$, body temperature $)$ from $0.1 \mathrm{MPA}$ to about $2 \mathrm{MPa}$. The IGA employs buoyancy correction, calculating the density of the gas phase using the PengRobinson EOS, to compensate for effects which can be appreciable at higher gas pressures. The buoyancy corrected absorption is recorded as mass percent increase relative to the original mass of the sample, which can then be converted to mole fraction of gas absorbed. 30-100 mg of BVO was used in the measurements described below. For this calculation, the nominally reported molar mass for BVO (1090 g/mol) was used; however, the effect of molar mass uncertainty by \pm 2 bromine atoms $(159.8 \mathrm{~g} / \mathrm{mol})$ is examined in the Supplementary Information. The authors note that although this uncertainty affects the absolute solubility and the Henry's constants, the comparison of the relative solubilities of $\mathrm{N}_{2} \mathrm{O}$ and $\mathrm{CO}_{2}$ remains valid as their molar masses differ only in the third decimal place. 


\section{Results and Discussion}

\subsection{Melting Point}

Although it is well known that the BVO mixtures are liquids, thermal data describing the phase transition is not present in the literature. Measurements are complicated by the fact that the sample is a mixture and also by the tendency of long chain species, such as polymers, oils and lipid ionic liquids, to exhibit thermal hysteresis. Specifically, we have observed lipidic ionic liquids to solidify into a mostly amorphous solids, then exhibit an exotherm prior to the melt, indicative of chain motion leading to a more ordered solid prior to the transition to an isotropic liquid. This behavior was observed with the BVO sample as well. The DSC traces for several different pretreatments, corresponding to different thermal histories, are shown in Figure 1. In the initial DSC trace (a), only the pretreatment described in the experimental section was used and an exotherm is observed approximately 30 degrees lower than the final melt. This exotherm then transitions into the endothermic event corresponding to the transition to the isotropic liquid, making melting point determination from the DSC trace problematic. As we have previously done with lipidic ionic liquids, the thermal behavior can be simplified by heating to induce the ordering event followed by immediate cooling, then heating to observe the melt. For the BVO sample, we observed that although the DSC trace was simplified by this procedure, it was not reduced to a single thermal event corresponding to the transition to the isotropic liquid, likely because the sample is a mixture of brominated triacylglycerols, rather than a pure compound. As such we attempted to simplify the DSC trace by heating to several intermediate temperatures before cooling back to $-80^{\circ} \mathrm{C}$ and heating to the final temperature: (b) $-31^{\circ} \mathrm{C}$, the center of the exotherm; (c) $-18^{\circ} \mathrm{C}$, the center of the plateau after the exotherm; (d) $-13^{\circ} \mathrm{C}$ the beginning of the final endothermic event and (e) $-11^{\circ} \mathrm{C}$, the bottom of the final endothermic event. Although the 
behavior never resolves to a single thermal event, there is a clear evolution of the DSC traces to a more uniform mixture melt between $-11^{\circ} \mathrm{C}$ and $-3^{\circ} \mathrm{C}$, with all of the mixture transitioning to the isotropic liquid by $-3^{\circ} \mathrm{C}$.

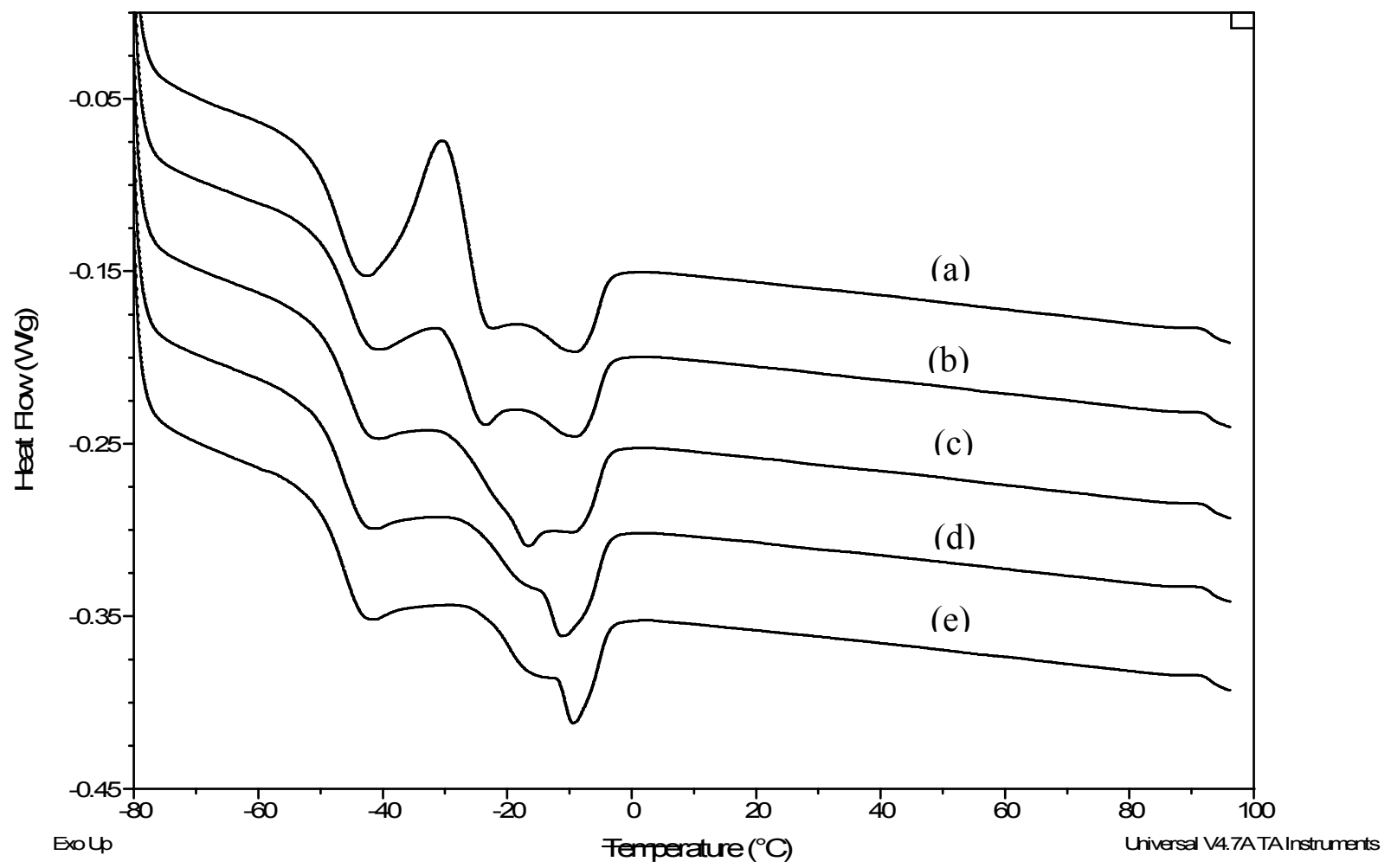

Figure 1. DSC traces for the melt of the BVO sample. Each sample was held at $100^{\circ} \mathrm{C}$ for 10 minutes, followed by cooling to $-80^{\circ} \mathrm{C}$. The initial DSC scan (a) was then heated to $100^{\circ} \mathrm{C}$. Scans (b)-(e) were heated to an intermediate temperature,(b) $-31^{\circ} \mathrm{C}$, (c) $-18^{\circ} \mathrm{C}$, (d) $-13^{\circ} \mathrm{C}$, (e) $11^{\circ} \mathrm{C}$, cooled to $-80^{\circ}$, and then heated to $100^{\circ} \mathrm{C}$. In all cases the heating/cooling rate was $10^{\circ} \mathrm{C} / \mathrm{min}$ and these traces show the final heating scan. The y axis values have been offset, but not rescaled.

\subsection{Density}

The density of BVO was measured at atmospheric pressure from $273.15 \mathrm{~K}$ to $343.15 \mathrm{~K}$ and the data is shown in Table 2. The data was fit to a linear expression in temperature (eq. 2) using a 
least squares method and the residual standard deviation was calculated using eq. 3. The model parameters and residual standard deviation are shown in Table 3.

$$
\begin{aligned}
& \rho\left(\mathrm{kg} / \mathrm{m}^{3}\right)=a+b \cdot T(K) \\
& s=\sqrt{\frac{1}{n_{d}-n_{p}} \sum_{i=1}^{N}\left(\rho_{\text {calc }}-\rho_{\text {exp }}\right)^{2}}
\end{aligned}
$$

Table 2. Density $\left(\rho, \mathrm{kg} \cdot \mathrm{m}^{-3}\right)$ of BVO as a function of temperature $( \pm 0.01 \mathrm{~K})$ at atmospheric pressure with standard uncertainty calculated as the standard deviation of the mean.

\begin{tabular}{cc}
$T / K$ & $\rho / \mathrm{kg} \cdot \mathrm{m}^{-3}$ \\
\hline 273.15 & 1344.4 \\
278.15 & 1339.9 \\
283.16 & 1335.5 \\
288.16 & 1331.0 \\
293.15 & 1326.6 \\
298.15 & 1322.2 \\
303.15 & 1317.7 \\
308.15 & 1313.3 \\
313.15 & 1309.0 \\
318.15 & 1304.5 \\
323.15 & 1300.1 \\
328.15 & 1295.8 \\
333.15 & 1291.5 \\
338.15 & 1287.2 \\
343.15 & 1282.9 \\
\hline
\end{tabular}

The uncertainty of the density measurements is $0.3 \mathrm{~kg} \cdot \mathrm{m}^{-3}$

Table 3. Coefficients for the linear fits of the density (eq. 2) as a function of temperature, with the residual standard deviation calculated by eq. 3 .

\begin{tabular}{cccc}
$\begin{array}{c}a \\
\mathrm{~kg} \cdot \mathrm{m}^{-3}\end{array}$ & $\begin{array}{c}B \\
\mathrm{~kg} \cdot \mathrm{m}^{-3} \cdot \mathrm{K}^{-1}\end{array}$ & $R^{2}$ & $\begin{array}{c}s \\
\mathrm{~kg} \cdot \mathrm{m}^{-3}\end{array}$ \\
\hline 1584.4 & -0.87941 & 0.99996 & 0.1
\end{tabular}


The experimental data and model fit are shown in Figure 2. The density is high compared with other nonpolar liquids, however it is consistent with the density commonly referenced for BVO $\left(\sim 1300 \mathrm{~kg} / \mathrm{m}^{3}\right)$ and with that of other brominated compounds. As with other liquids, the density decreases slightly with temperature as the liquid expands.

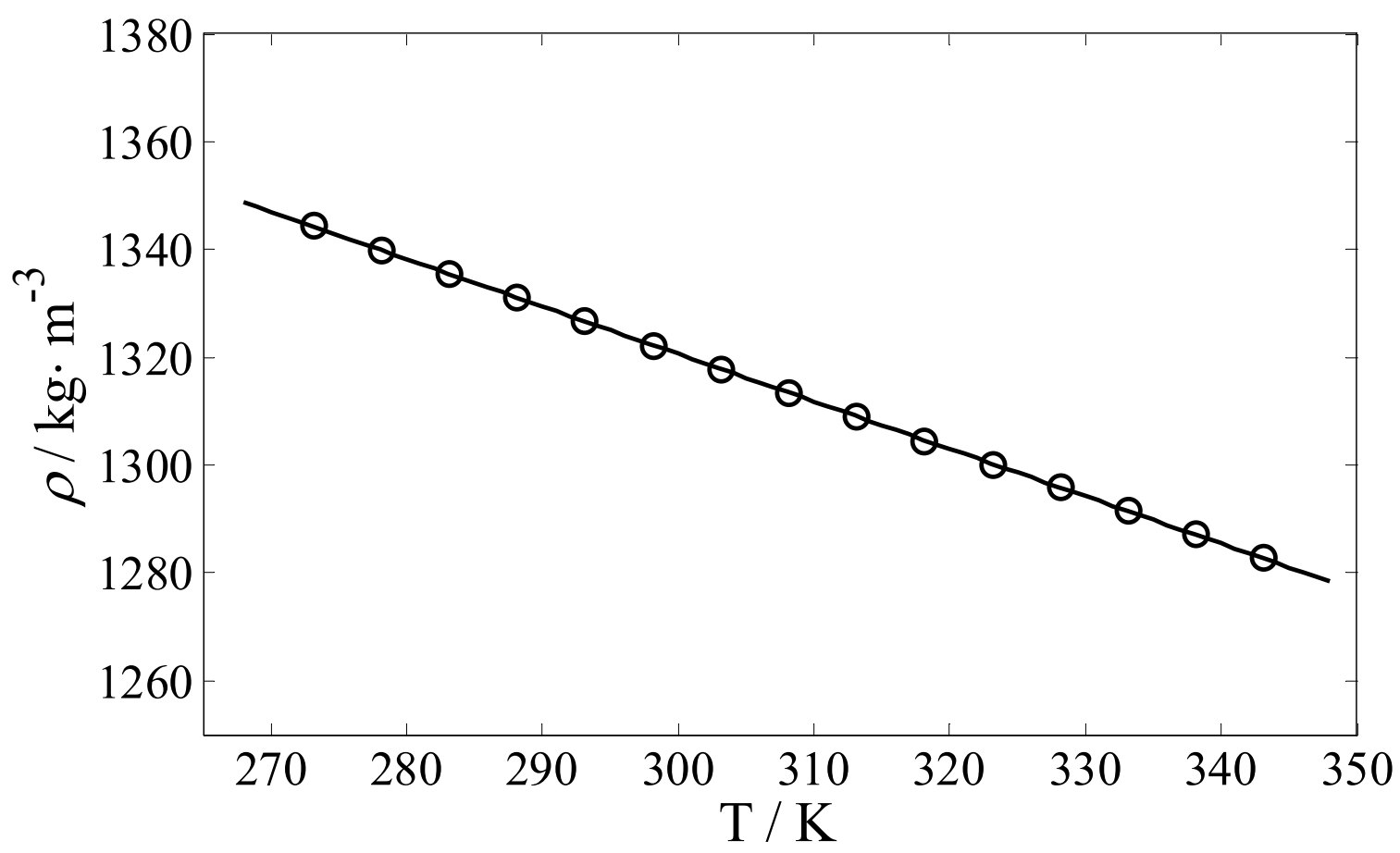

Figure 2. Density $\left(\rho, \mathrm{kg} \cdot \mathrm{m}^{-3}\right)$ of BVO as a function of temperature at atmospheric pressure. The line represents the linear fit of eq. 2 .

From the temperature dependent density data, the volume expansivity may be calculated from eq. 4 .

$$
\alpha_{P}=-\frac{1}{\rho}\left(\frac{\partial \rho}{\partial T}\right)_{P}
$$


The values for $\alpha_{P}$ are shown in Table 4 and are plotted as a function of temperature in Figure 3. Similar to longer $n$-alkanes at low pressure,[17] the volume expansivity increases with temperature as the higher amount of available thermal energy is able to overcome more of the dispersion forces and allow the liquid to expand more at higher temperatures.

Table 4. Volume expansivity $\left(\alpha_{\mathrm{P}}\right)$ of $\mathrm{BVO}$ as a function of temperature $( \pm 0.01 \mathrm{~K})$.

\begin{tabular}{ll}
$T / K$ & $\alpha_{P} / \mathrm{K}^{-1}$ \\
\hline 273.15 & 654.1 \\
278.15 & 656.3 \\
283.16 & 658.5 \\
288.16 & 660.7 \\
293.15 & 662.9 \\
298.15 & 665.1 \\
303.15 & 667.4 \\
308.15 & 669.6 \\
313.15 & 671.8 \\
318.15 & 674.1 \\
323.15 & 676.4 \\
328.15 & 678.7 \\
333.15 & 680.9 \\
338.15 & 683.2 \\
343.15 & 685.5 \\
\hline
\end{tabular}




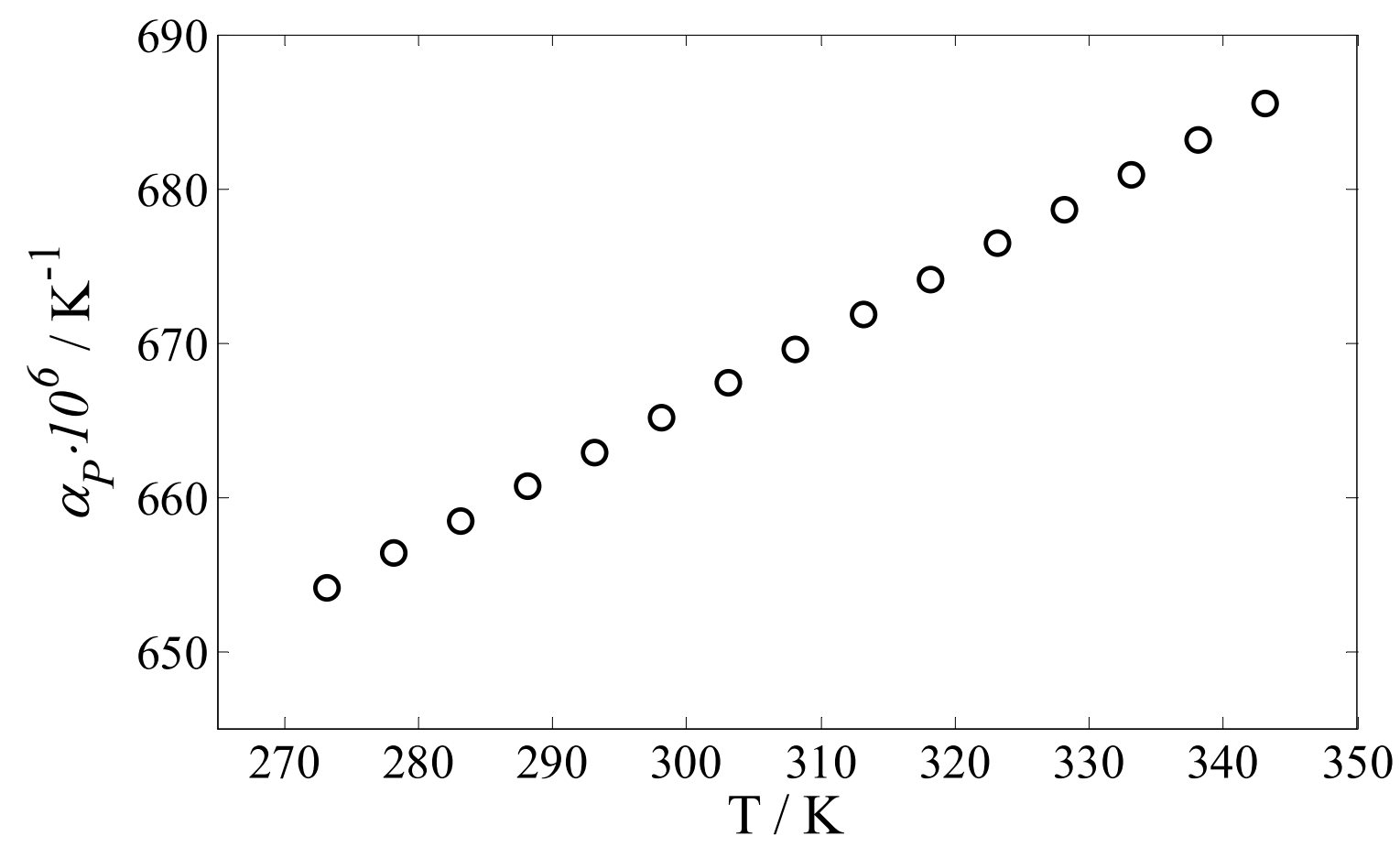

Figure 3. Volume expansivity $\left(\alpha \mathrm{P}, \mathrm{K}^{-1}\right)$ of $\mathrm{BVO}$ as a function of temperature at atmospheric pressure as calculated by eq. 4 .

\subsection{Viscosity}

The viscosity of BVO was measured at atmospheric pressure from $305.65 \mathrm{~K}$ to $363.15 \mathrm{~K}$ and the values are shown in Table 5. The data was fit using a least squares method to two models: an Arrhenius-type model (eq. 5) with two parameters and the Vogel-Fulcher-Tamman (VFT)[1820] model (eq. 6), which has three parameters.

$$
\begin{aligned}
& \eta(m P a \cdot s)=\eta_{\infty} \exp \left(\frac{-E_{a}}{R T}\right) \\
& \eta(m P a \cdot s)=A \exp \left(\frac{k}{T(K)-T_{0}}\right)
\end{aligned}
$$


Table 5. Dynamic viscosity $(\eta)$ of BVO as a function of temperature $( \pm 0.01 \mathrm{~K})$ at atmospheric pressure with standard uncertainty, $u$, calculated as the standard deviation of the mean.

\begin{tabular}{ccc}
$T / K$ & $\eta / \mathrm{mPa} \cdot \mathrm{s}$ & $\pm u / \mathrm{mPa} \cdot \mathrm{s}$ \\
\hline 305.65 & 2059 & 2 \\
308.15 & 1685 & 2 \\
313.15 & 1167 & 2 \\
318.15 & 818.9 & 0.3 \\
323.15 & 591.9 & 0.4 \\
328.15 & 437.2 & 0.3 \\
333.15 & 329.1 & 0.2 \\
338.15 & 253 & 0.2 \\
343.15 & 197.3 & 0.1 \\
348.15 & 156.8 & 0.1 \\
353.15 & 126.2 & 0.1 \\
358.15 & 103.1 & 0.1 \\
363.15 & 84.8 & 0.1 \\
\hline
\end{tabular}

The uncertainty of the viscosity measurements are given individually for each temperature.

For each model, the residual standard deviation was calculated using eq. 7:

$$
s=\sqrt{\frac{1}{n_{d}-n_{p}} \sum_{i=1}^{N}\left(\eta_{\text {calc }}-\eta_{\exp }\right)^{2}}
$$

The parameters for each model as well as the residual standard deviations are shown in Table 6. An F test was performed and determined that the three parameter VFT expression provided the better statistical fit. A plot of the experimental data and the VFT fit is shown in Figure 4. The viscosity exhibits a typical exponential decrease with temperature although, as discussed below, it is considerably higher than other unmodified oils. 
Table 6. Coefficients for the Arrhenius and VFT models (eq. 5 and 6, respectively) of BVO as a function of temperature at atmospheric pressure with the model standard deviation calculated by eq. 7.

\begin{tabular}{|c|c|c|c|c|c|c|c|c|}
\hline \multicolumn{4}{|c|}{ Arrhenius Model } & \multicolumn{5}{|c|}{ VFT Model } \\
\hline$\eta_{\infty}$ & $E_{a}$ & $R^{2}$ & $s$ & $A$ & $k$ & $T_{0}$ & $R^{2}$ & $S$ \\
\hline $\mathrm{mPa} \cdot \mathrm{s}$ & $\mathrm{kJ} \cdot \mathrm{mol}^{-1}$ & & $\mathrm{mPa} \cdot \mathrm{s}$ & $\mathrm{mPa} \cdot \mathrm{s}$ & $\mathrm{K}$ & $\mathrm{K}$ & & $\mathrm{mPa} \cdot \mathrm{s}$ \\
\hline $4.169 \cdot 10^{-7}$ & -56.68 & 0.9989 & 20 & 0.06648 & 1323 & 177.7 & 0.999988 & 2 \\
\hline
\end{tabular}

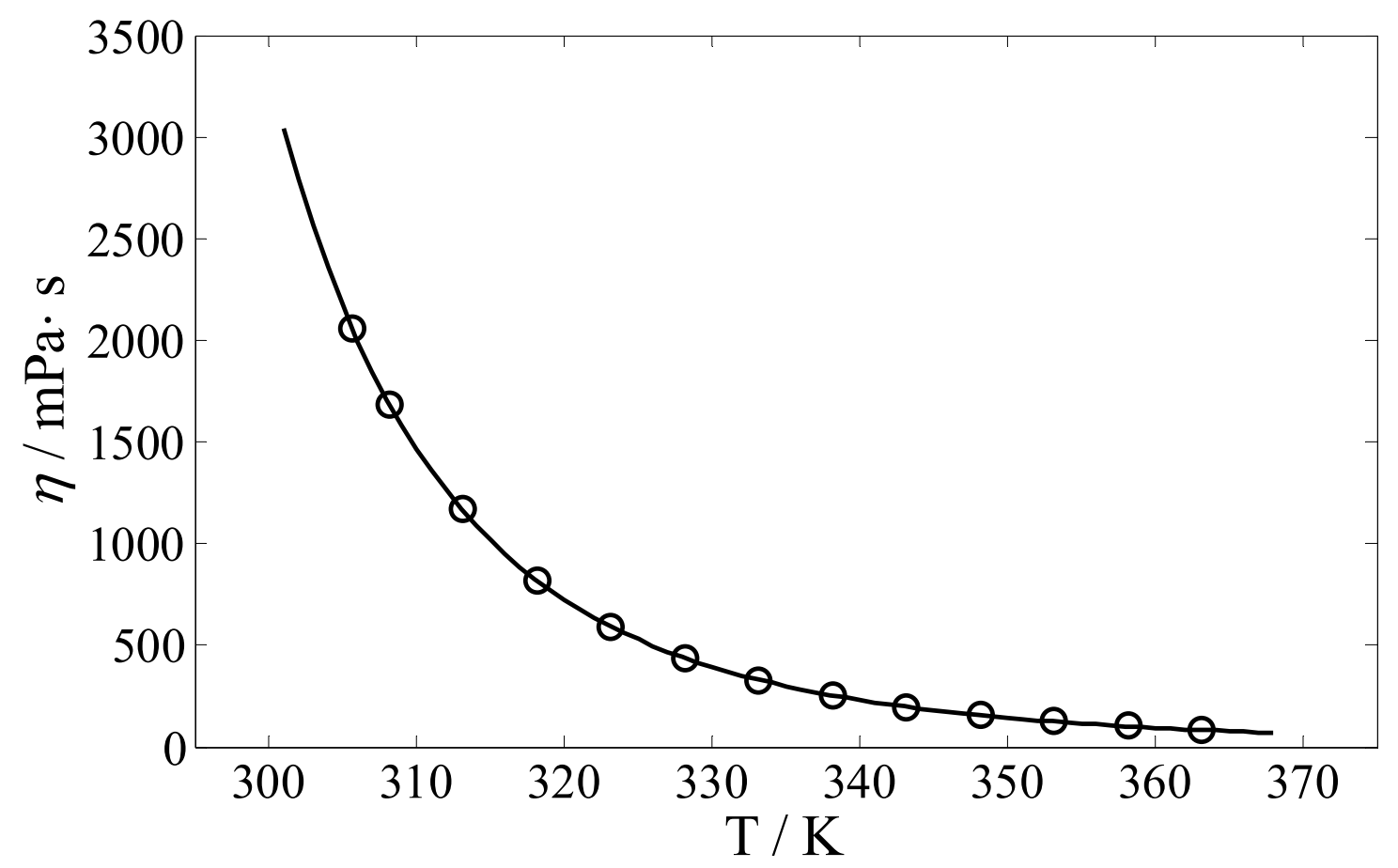

Figure 4. Dynamic viscosities ( $\eta, \mathrm{mPa} \cdot \mathrm{s})$ of $\mathrm{BVO}$ as a function of temperature at atmospheric pressure. The line represents the VFT fit (eq. 6) of the data. 


\subsection{Refractive Index}

The refractive index for BVO was measured at atmospheric pressure from $273.15 \mathrm{~K}$ to 353.15 $\mathrm{K}$ and the data is shown in Table 7. The data was fit to a linear model (eq. 8, with fit constants $d_{0}$ and $d_{1}$ ) in absolute temperature with a least squares method with residual standard deviation calculated using eq. 9:

$$
\begin{aligned}
& n_{D}=d_{0}+d_{1} \cdot T(K) \\
& s=\sqrt{\frac{1}{n_{d}-n_{p}} \sum_{i=1}^{N}\left(n_{D, \text { calc }}-n_{\mathrm{D}, \exp }\right)^{2}}
\end{aligned}
$$

The model parameters and residual standard deviation are shown in Table 8. A plot of the experimental data, along with the linear fit, is shown in Figure 5. As is common for most liquids, the refractive index decreases with temperature as the liquid expands, the molar volume decreases and a given incident photon interacts with fewer molecules as it travels through the liquid. 
Table 7. Refractive indices $\left(n_{D}\right)$ of BVO as a function of temperature $( \pm 0.1 \mathrm{~K})$ at atmospheric pressure with the standard uncertainty, $u$, based on average deviation from calibration standards at each temperature.

\begin{tabular}{ccc}
$T / K$ & $n_{D}$ & $\pm u$ \\
\hline 273.15 & 1.5187 & 0.0001 \\
278.15 & 1.5171 & 0.0001 \\
283.15 & 1.5153 & 0.0002 \\
288.15 & 1.5132 & 0.0003 \\
293.15 & 1.5112 & 0.0001 \\
298.15 & 1.5096 & 0.0002 \\
303.15 & 1.5074 & 0.0001 \\
308.15 & 1.5060 & 0.0001 \\
313.15 & 1.5043 & 0.0001 \\
318.15 & 1.5025 & 0.0001 \\
323.15 & 1.5004 & 0.0001 \\
328.15 & 1.4986 & 0.0001 \\
333.15 & 1.4965 & 0.0001 \\
338.15 & 1.4950 & 0.0001 \\
343.15 & 1.4929 & 0.0001 \\
348.15 & 1.4917 & 0.0001 \\
353.15 & 1.4899 & 0.0001 \\
\hline
\end{tabular}

The uncertainty of the refractive index measurements are given individually for each temperature.

Table 8. Coefficients for the linear fit of the refractive index (eq. 8) as a function of temperature, with the residual standard deviation calculated by eq. 9 .

\begin{tabular}{cccc}
$d_{0}$ & $d_{1} / K^{-1}$ & $R^{2}$ & $s$ \\
\hline 1.6182 & $-3.6417 \times 10^{-4}$ & 0.9994 & 0.0002
\end{tabular}




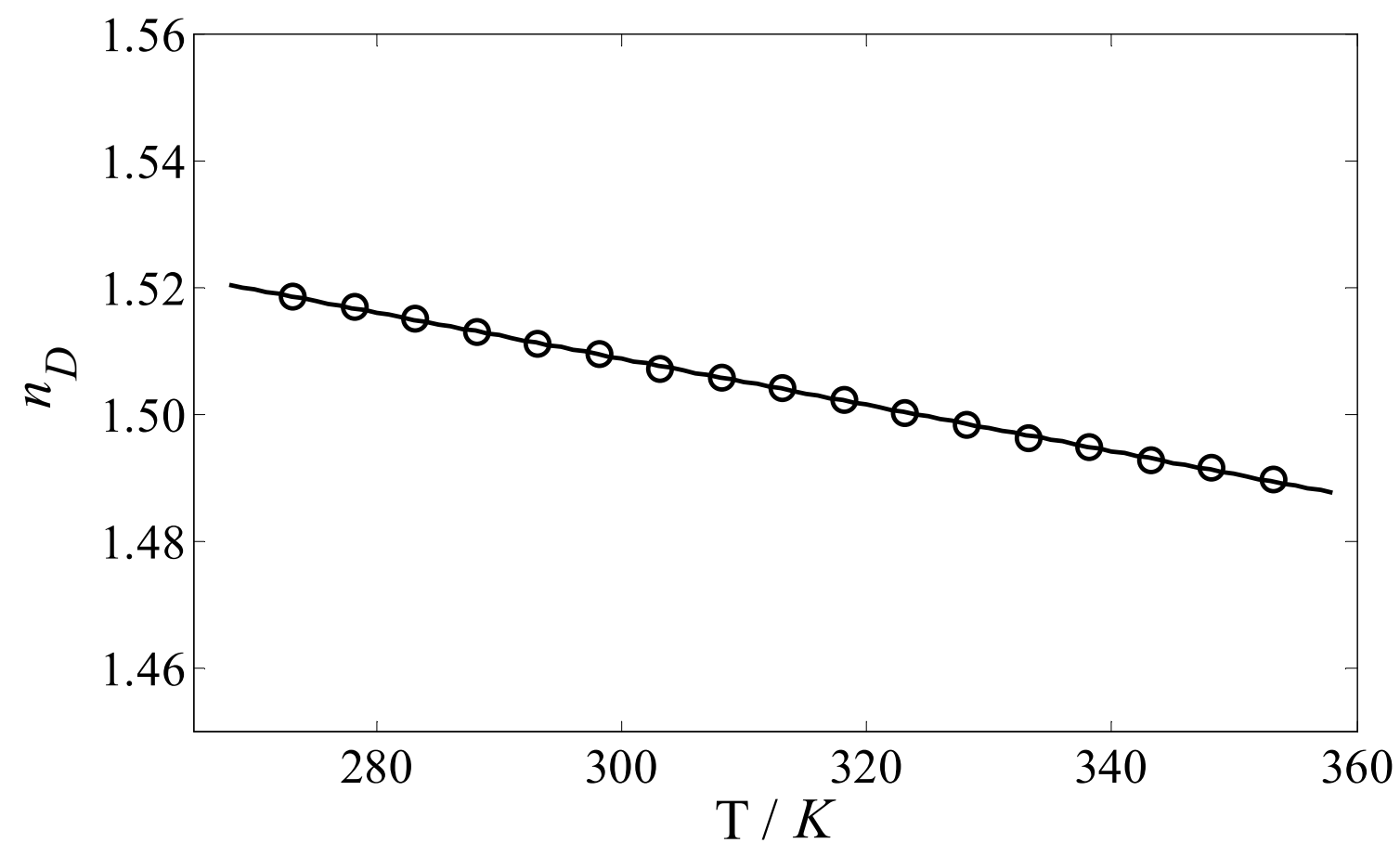

Figure 5. Refractive indices $\left(n_{D}\right)$ of $\mathrm{BVO}$ as a function of temperature at atmospheric pressure. The line represents the linear fit of the data (eq. 8).

\subsection{Heat Capacity}

The liquid phase heat capacity data for BVO was measured at atmospheric pressure from 278.15 $\mathrm{K}$ to $408.15 \mathrm{~K}$ and the data is shown in Table 9. The heat capacity data was fit to a quadratic equation in absolute temperature (eq. 10) using a least squares method and the residual standard deviation was calculated with eq. 11; the coefficients and standard deviation are shown in Table 10.

$$
\begin{aligned}
& C_{p}(J / g \cdot K)=A+B \cdot T(K)+C \cdot[T(K)]^{2} \\
& S=\sqrt{\frac{1}{n_{d}-n_{p}} \sum_{i=1}^{N}\left(C_{p, \text { calc }}-C_{p, \exp }\right)^{2}}
\end{aligned}
$$

The experimental heat capacity data along with the model fit are shown in Figure 6. 
Table 9. Liquid phase heat capacity $\left(C_{p}, \mathrm{~J} \cdot \mathrm{g}^{-1} \cdot \mathrm{K}^{-1}\right)$ of $\mathrm{BVO}$ as a function of temperature $( \pm 0.01$ $\mathrm{K})$ at atmospheric pressure with standard uncertainty, $u$, calculated as the standard deviation of the mean.

\begin{tabular}{ccc}
$T$ & $\begin{array}{c}C_{p} \\
\mathrm{~K}\end{array}$ & $\begin{array}{c} \pm u \\
\mathrm{~J} / \mathrm{g} \cdot{ }^{\circ} \mathrm{C}\end{array}$ \\
\hline & & $\mathrm{J} / \mathrm{g} \cdot{ }^{\circ} \mathrm{C}$ \\
\hline 278.15 & 1.522 & 0.007 \\
288.15 & 1.541 & 0.007 \\
308.15 & 1.563 & 0.008 \\
318.15 & 1.586 & 0.008 \\
328.15 & 1.610 & 0.008 \\
338.15 & 1.632 & 0.008 \\
348.15 & 1.657 & 0.009 \\
358.15 & 1.680 & 0.009 \\
368.15 & 1.705 & 0.009 \\
378.15 & 1.73 & 0.01 \\
388.15 & 1.76 & 0.01 \\
398.15 & 1.78 & 0.01 \\
408.15 & 1.81 & 0.01 \\
\hline
\end{tabular}

The uncertainty of the heat capacity measurements are given individually for each temperature.

Table 10. Coefficients for the quadratic fit of the heat capacity (eq. 10) as a function of temperature, with the residual standard deviation, $s$, calculated by eq. 11 .

\begin{tabular}{ccccc}
$\boldsymbol{a}$ & $\boldsymbol{b}$ & $\boldsymbol{c}$ & \multicolumn{1}{c}{$\boldsymbol{R}^{\mathbf{2}}$} & $\mathbf{J}$ \\
$\mathbf{J} / \mathbf{g ~ K}$ & $\mathbf{J} / \mathbf{g ~ K}^{\mathbf{2}}$ & $\mathbf{J} / \mathbf{g ~ K}^{\mathbf{3}}$ & & 0.002 \\
\hline 1.061 & $1.130 \times 10^{-3}$ & $1.868 \times 10^{-6}$ & 0.9996 &
\end{tabular}




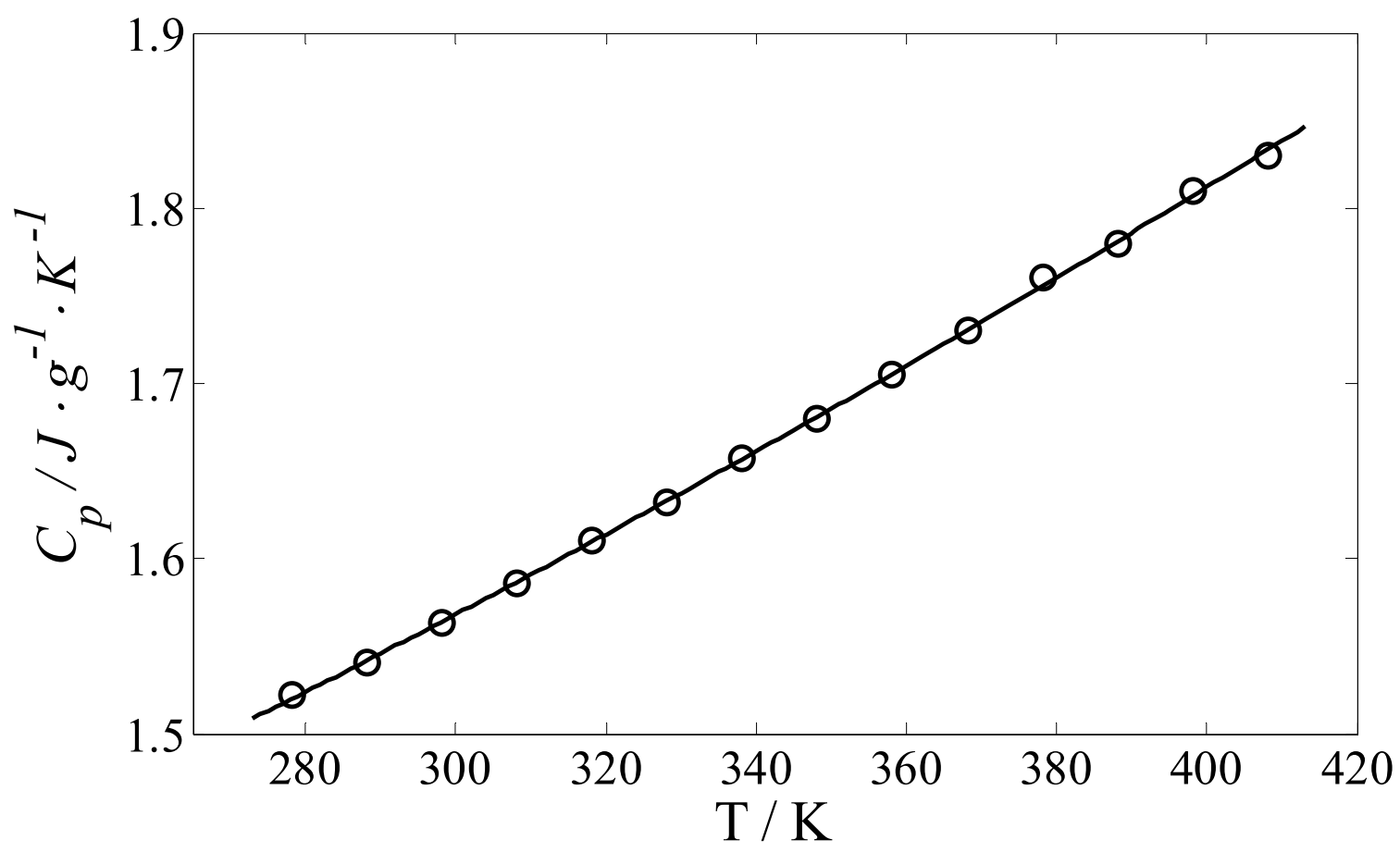

Figure 6. Liquid phase heat capacity $\left(C_{p}, \mathrm{~J} \cdot \mathrm{g}^{-1} \cdot \mathrm{K}^{-1}\right)$ of $\mathrm{BVO}$ as a function of temperature at atmospheric pressure. The line represents the quadratic fit of the data (eq. 10).

\subsection{Comparison of the Properties of BVO with Unmodified Natural Oils}

The effect of brominating the soybean oil on its thermophysical properties is evident by comparing the properties measured above to those of unmodified soybean oil. To enhance the comparison and elucidate the trends and differences between the natural oils, literature values for canola (rapeseed), corn, grapeseed and sunflower oil are included in the comparison of density, viscosity and heat capacity.[21, 22]

Figure 7 shows the temperature dependent density for the BVO as well as each of the natural oils.[21] While the density of the natural oils are virtually indistinguishable, $\sim 900 \mathrm{~kg} \cdot \mathrm{m}^{-3}$, the density of BVO is considerably higher, $\sim 1300 \mathrm{~kg} \cdot \mathrm{m}^{-3}$. This $44 \%$ increase in density is expected due to the addition of heavy bromine atoms to the molecule and is the fundamental reason that BVO is used in the beverage industry. When the volume expansivity of BVO is compared to 
that calculated from the temperature dependent density of soybean oil, the values for BVO are slightly lower $(<5 \%)$ for the same temperature.

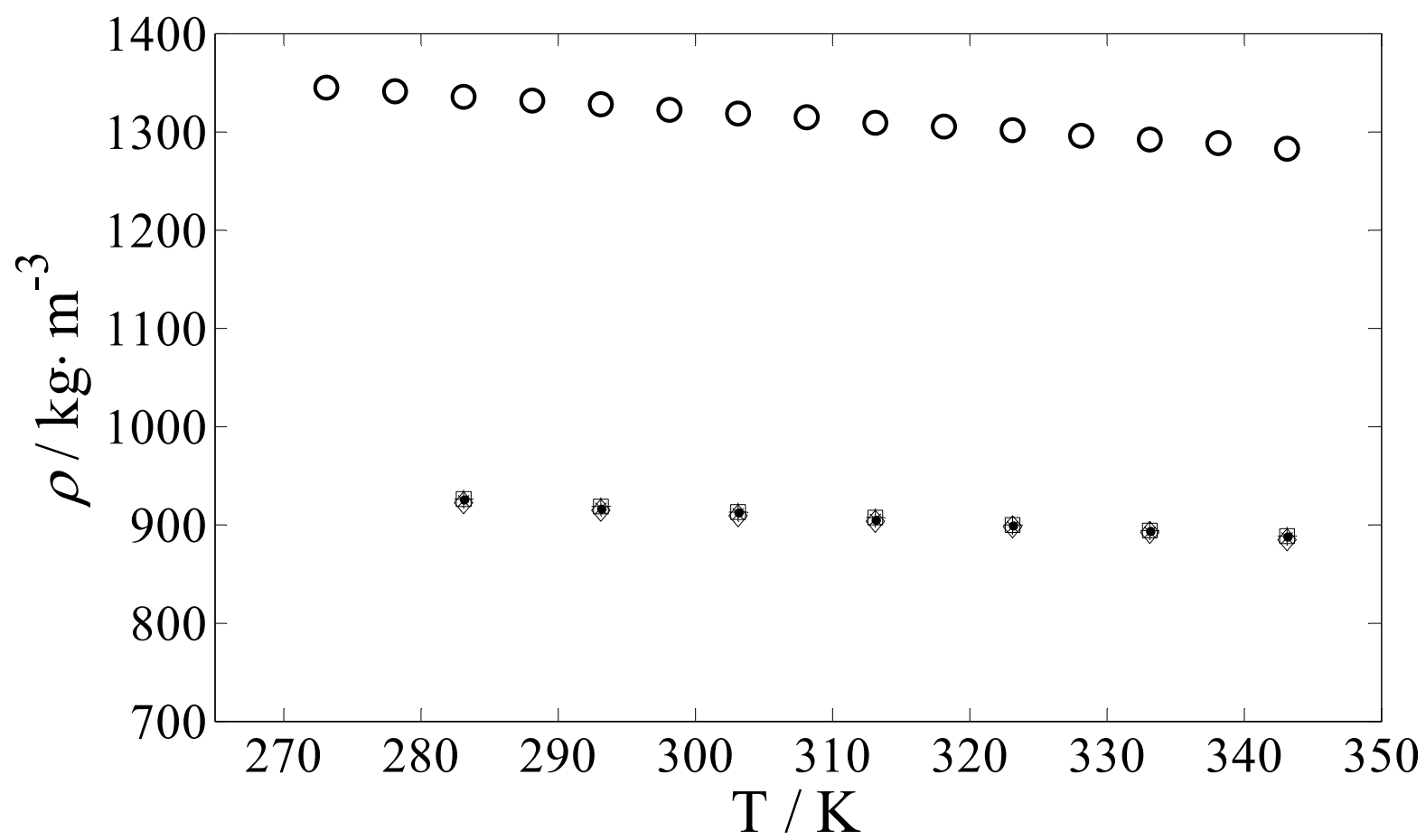

Figure 7. Comparison of the density $\left(\rho, \mathrm{kg} \cdot \mathrm{m}^{-3}\right)$ of BVO (०) with that of unmodified natural oils: soybean $(\square)$, canola (rapeseed, $\diamond)$, corn $(x)$, grapeseed $(+)$ and sunflower $(\bullet) .[21]$ Note: the natural oil markers overlap significantly.

Like its density, the viscosity of BVO is considerable higher (by an order of magnitude or more) than that of the unmodified oils,[21] which, like their densities, are all very similar. The trend is shown on a semilog plot of viscosity vs. temperature in Figure 8. Although an increase in viscosity was anticipated, the magnitude demonstrates a significant increase in viscous forces which likely arise from the large polarizability of bromine, the partial charges induced by bromine, or a combination of these effects. 


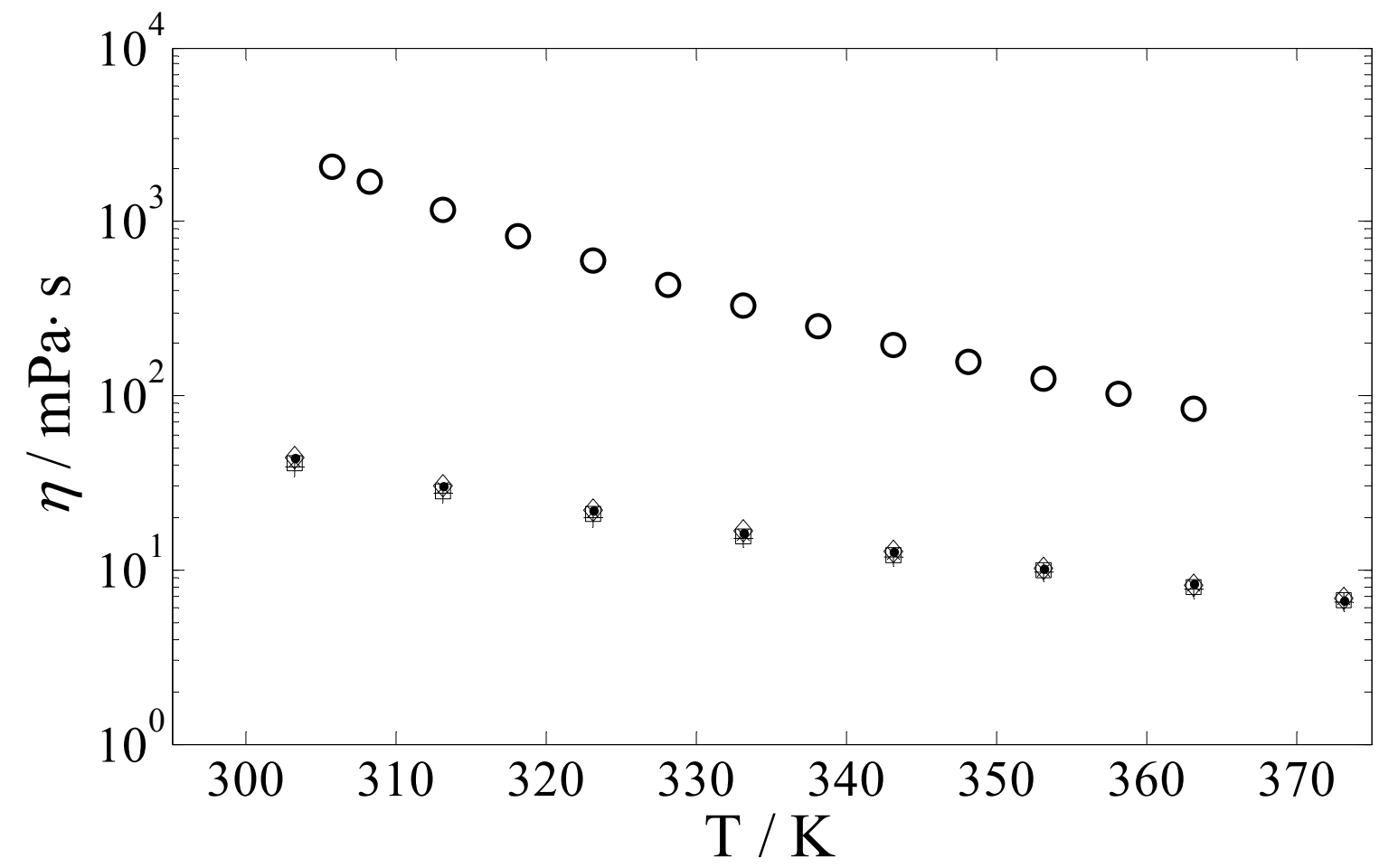

Figure 8. Comparison of the dynamic viscosity ( $\eta, m P a \cdot s)$ of BVO (o) with that of unmodified natural oils: soybean $(\square)$, canola (rapeseed, $\diamond)$, corn $(x)$, grapeseed $(+)$ and sunflower $(\bullet) .[21]$ Note: the natural oil markers overlap significantly.

Interestingly, as $99+\%$ of the double bonds in natural oils are cis, and bromination occurs with anti stereochemistry, the bulky bromines will likely force the chain backbone into a cisoid configuration (to remain anti to each other with respect to the dihedral angle about the Br-C-C$\mathrm{Br}$ bonds). This stereochemical artifact may be responsible for the lower melting point, relative to the hydrogenated triacylglycerol. Such a conformation may enhance the polarity/polarizability about the brominated carbons, resulting in stronger intermolecular forces, while the cisoid confirmation could decrease solid phase packing efficiency, lowering the melting point. Ongoing studies are investigating this phenomenon for shorter chain dibrominated analogs; however, the cause of the significant increase in viscosity with bromination, whether originating through increased polarity due to induction or originating 
through enhanced dispersion forces due to the large size bromine atoms, can be elucidated by examining the literature viscosity data[23] for a homologous series of halogenated alkene; specifically, the 3,4-dihalo derivatives of cis-2-butene. If the viscosity increases as the series progresses from difluoro, dichloro, dibromo to diiodo, then it can be ascertained that the increase in atomic size, and resulting increase in polarizability and dispersion forces, are responsible for the increase in viscosity. However, if the viscosity decreases as the series progresses as state above, then it can be ascertained that the increase in electronegativity and resulting increase in polarity through induction are responsible for the increase in viscosity. Figure 9 shows the viscosity of this series with data taken from the literature.

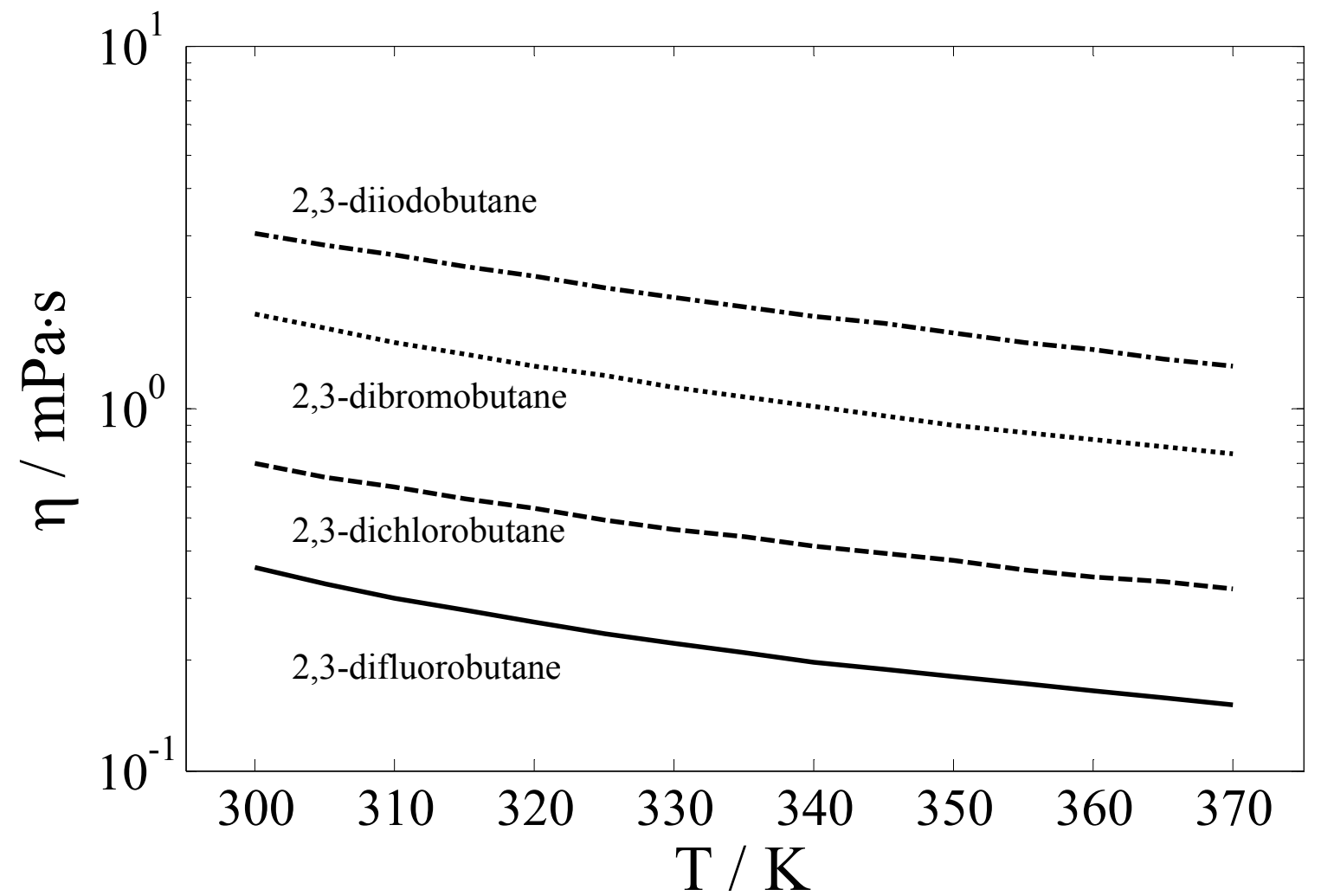

Figure 9. Comparison of the viscosity of 2,3-dihalobutenes as a function of temperature. [23]

As is evident from Figure 9, the viscosity increases with the size of the halogen atom, indicating that the increase in viscosity is due to enhanced dispersion forces due to the greater 
polarizability of the larger halogen atoms, and that any inductive effects due to electronegativity are not significant. This reasoning likely extends to BVO, with the increase in viscosity upon bromination arising from enhanced dispersion forces.

Lastly, Figure 10 shows the temperature dependent liquid phase heat capacity of BVO along with that of the natural oils.[22] As expected, bromination has little effect on the heat capacity, and the $\mathrm{BVO}$ values lie within the variation of the natural oils. The addition of $\mathrm{Br}_{2}$ across the double bonds of soybean oil changes relatively few bonds on the large triacylglycerol and has little impact on the heat capacity, with that of BVO being slightly lower than that of soybean oil on a per gram basis, likely due to the significant increase in molar mass.

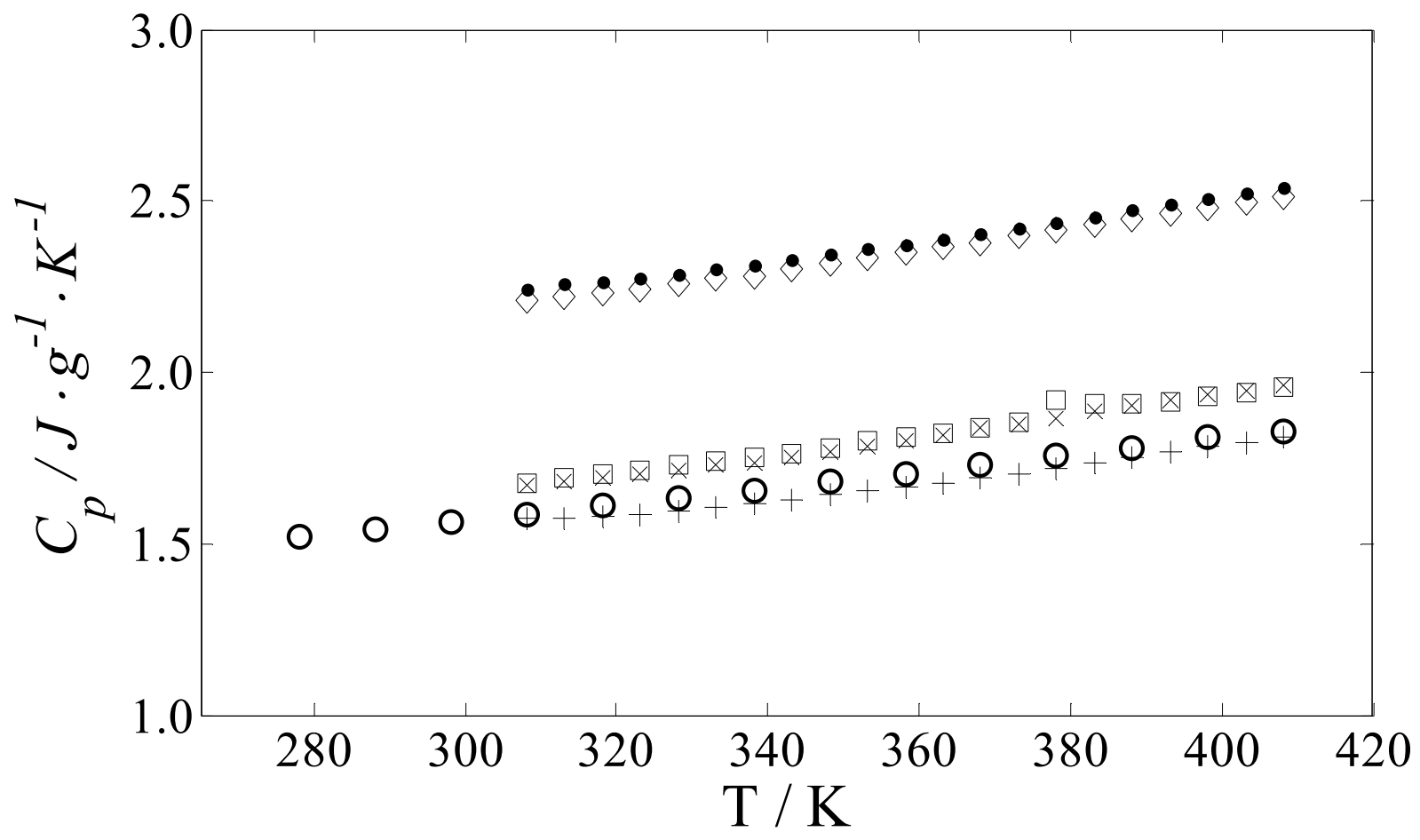

Figure 10. Comparison of the liquid phase heat capacity $\left(C_{p}, \mathrm{~J} \cdot \mathrm{g}^{-1} \cdot \mathrm{K}^{-1}\right)$ of BVO (०) with that of unmodified natural oils: soybean $(\square)$, canola (rapeseed, $\diamond)$, corn $(\mathrm{x})$, grapeseed $(+)$ and sunflower (•).[22] 


\subsection{Comparison of the $\mathrm{CO}_{2}$ and $\mathrm{N}_{2} \mathrm{O}$ solubility Properties of BVO with Unmodified Natural Oils}

The solubility data for $\mathrm{CO}_{2}$ and $\mathrm{N}_{2} \mathrm{O}$ in $\mathrm{BVO}$ are shown below in Tables $\mathbf{1 1}$ and $\mathbf{1 2}$, respectively, with the data shown graphically in Figure 11. The data has been correlated using the Krichevsky-Kasarnovsky[24] equation, eq. 12, which is often use for systems of volatile gases in mixtures with low volatility liquids. The equation relates the pure component fugacity of the gaseous component at the temperature and pressure of interest (obtained from the NIST REFPROP program[25-27]) with the liquid phase mixture fugacity as given below.

$$
f_{1}^{v}=f_{1}^{L}=x_{1} H_{1,2} \exp \left[\frac{V_{1}^{\infty}\left(p-p_{2}^{S}\right)}{R T}\right]
$$

In eq. $12, f_{1}^{V}$ is the fugacity of the pure gas, $x_{1}$ is the solubility of the gas (1) in the solvent (2), $H_{1,2}$ is the Henry's constant for species 1 in $2, V_{1}^{\infty}$ is the infinite dilution partial molar volume of $1, p$ is the total pressure and $p_{2}^{s}$ is the vapor pressure of the solvent. The term in the exponent represents the ratio of the fugacity of the solute (1), infinitely dilute in the solvent (2) at the solvent's vapor pressure, to the fugacity of (1) at the pressure of the system. This is a correction for a Henry's law reference state that corrects for pressures above that of the vapor pressure of the solvent. As the vapor pressure of the BVO is virtually negligible, $p_{2}^{s}$ can be taken as zero. Rearranging the expression yields:

$$
\ln \left(\frac{f_{1}^{V}}{x_{1}}\right)=\ln H_{1,2}+\frac{V_{1}^{\infty} p}{R T}
$$

The left hand side of the equation may be plotted vs the pressure to obtain, via a least-squares fit, the slope as the infinite dilution molar volume of the gas divided by RT and the intercept is the natural $\log$ of the Henry's constant. For these systems the data taken at $0.5 \mathrm{MPa}$ and higher were used to fit the equation with parameters given in Table 13. 
Table 11. Solubility of $\mathrm{CO}_{2}(1)$ in $\mathrm{BVO}(2)$ at $310 \mathrm{~K}\left(37^{\circ} \mathrm{C}\right)$ as a function of pressure.

\begin{tabular}{ccc}
$\mathrm{T} / \mathrm{K}$ & Pressure / MPa & $100 \cdot \mathrm{x} 1$ \\
\hline 310.1 & 0.0101 & \\
310.1 & 0.0237 & 0.8 \\
310.1 & 0.0500 & 1.3 \\
310.1 & 0.0752 & 2.1 \\
310.1 & 0.1002 & 2.9 \\
310.1 & 0.1253 & 3.6 \\
310.1 & 0.1502 & 4.4 \\
310.1 & 0.2507 & 5.2 \\
310.1 & 0.5009 & 8.4 \\
310.1 & 0.7498 & 15.5 \\
310.1 & 1.0003 & 21.7 \\
310.1 & 1.2504 & 27.5 \\
310.1 & 1.4992 & 32.7 \\
310.1 & 1.7500 & 37.3 \\
310.1 & 2.0010 & 41.4 \\
& & 44.5
\end{tabular}

Table 12. Solubility of $\mathrm{N}_{2} \mathrm{O}(1)$ in $\mathrm{BVO}(2)$ at $310 \mathrm{~K}\left(37^{\circ} \mathrm{C}\right)$ as a function of pressure.

\begin{tabular}{ccc}
$\mathrm{T} / \mathrm{K}$ & Pressure / MPa & $100 \cdot \mathrm{x} 1$ \\
\hline 310.1 & 0.0100 & \\
310.1 & 0.0249 & 0.6 \\
310.1 & 0.0500 & 1.3 \\
310.1 & 0.0754 & 2.4 \\
310.1 & 0.0999 & 3.5 \\
310.1 & 0.1255 & 4.6 \\
310.1 & 0.1496 & 5.6 \\
310.1 & 0.2504 & 6.4 \\
310.1 & 0.5009 & 11.0 \\
310.1 & 0.7502 & 19.3 \\
310.1 & 1.0010 & 26.9 \\
310.1 & 1.2510 & 33.2 \\
310.1 & 1.4995 & 38.5 \\
310.1 & 1.7503 & 43.3 \\
310.1 & 2.0010 & 47.3 \\
& & 50.5 \\
\hline
\end{tabular}


Table 13. Fit constants for eq. 13 for $\mathrm{CO}_{2}$ and $\mathrm{N}_{2} \mathrm{O}$ solubility in $\mathrm{BVO}$ at $37^{\circ} \mathrm{C}$. Standard uncertainties are calculated from the linear fit of equation 13, propagated using derivative uncertainty propagation for $\mathrm{H}$.

Dissolved Gas

\begin{tabular}{ccc} 
Dissolved Gas & $\mathrm{H}$ & $\mathrm{V}^{\infty}$ \\
& $(\mathrm{MPa})$ & $\left(\mathrm{cm}^{3} / \mathrm{mol}\right)$ \\
\hline $\mathrm{CO}_{2}$ & & \\
$\mathrm{~N}_{2} \mathrm{O}$ & $2.92 \pm 0.02$ & $440 \pm 10$ \\
& $2.26 \pm 0.01$ & $610 \pm 10$
\end{tabular}

Figure 11. Solubility of $\mathrm{CO}_{2}(\circ)$ and $\mathrm{N}_{2} \mathrm{O}(\square)$ in $\mathrm{BVO}$ at $310 \mathrm{~K}\left(37^{\circ} \mathrm{C}\right)$. The lines represent the model fits for eq. 13 for each data set. 
As demonstrate by Figure 11, the BVO exhibits $\sim 0.05$ higher mole fraction solubility for $\mathrm{N}_{2} \mathrm{O}$ than $\mathrm{CO}_{2}$, similar to that of the differential solubility in olive oil.[28] A direct comparison of these solubilities is shown in Figure 12. Of note is that the overall solubility of the two gases is lower in BVO than in the olive oil, but the enhanced solubility of $\mathrm{N}_{2} \mathrm{O}$ is observed in both systems to about the same degree. The overall decrease in gas solubility may be due to the bulky bromines occupying free volume in the liquid which was previously available for occupation by gas molecules. The preservation of the differential solubility for these two gases upon bromination indicates that the same would be expected upon bromination of a lipidic ionic liquid.

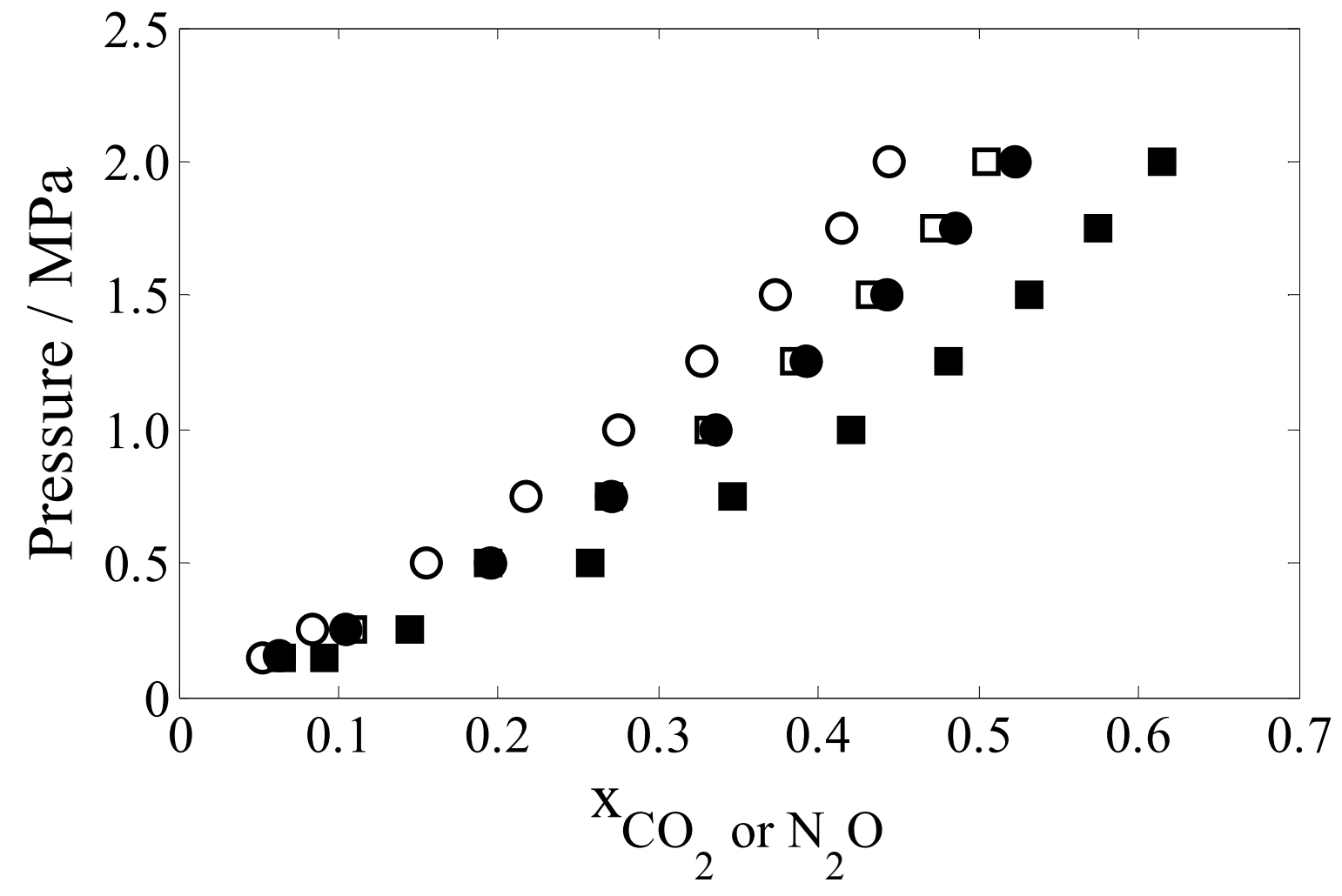

Figure 12. Comparison of the solubility of $\mathrm{CO}_{2}(\circ)$ and $\mathrm{N}_{2} \mathrm{O}(\square)$ in $\mathrm{BVO}$ with the solubility of $\mathrm{CO}_{2}(\bullet)$ and $\mathrm{N}_{2} \mathrm{O}(\boldsymbol{\bullet})$ in olive oil.[28] 


\section{Conclusions}

Brominated vegetable oil is a chemically modified soy bean oil used in the beverage industry as an emulsifier for citrus flavors. Although its nominal density, the key property for its use as a food additive, has widely been reported as $\sim 1300 \mathrm{~kg} \cdot \mathrm{m}^{-3}$, accurate literature values for its density and other thermophysical properties have not been available. Our interest in these properties stems from our work investigating the synthesis and characterization of lipidic ionic liquids: ionic liquids with significant non-polar content which remain liquids at room temperature. As bromination of triacylglycerols results in liquid mixtures, whereas hydrogenation of triacylglycerols results in solid mixtures, we anticipate the former synthetic technique to provide a means of creating room temperature lipidic ionic liquid which are more oxidativly stable than their unsaturated analogues.

In this work, the thermal and thermophysical properties (melting point, density, refractive index, viscosity, liquid phase heat capacity) of a commercially available brominated vegetable oil were measured and correlated to appropriate temperature dependent models. Additionally, several of these properties were compared to those of unmodified natural oils to elucidate the effect of bromination on the properties. While the density and viscosity increase significantly, the heat capacity is virtually unchanged relative to the unmodified oils. Increased density arises from the addition of massive bromine atoms to the oil; this has a significant effect on the density, however, the overall bonding structure of the molecule remains unchanged, resulting in little change in heat capacity. Analysis of literature data for the viscosity of molecular analogs consisting of a homologous series of dihalogenated butanes indicates that the origin of the significant viscosity increase upon bromination $(\sim 10$ times relative to the unmodified natural 
oils) is increased dispersion forces arising from the high polarizability of the added bromine atoms.

As a characteristic of many natural oils is their preferential solubility for $\mathrm{N}_{2} \mathrm{O}$ over $\mathrm{CO}_{2}$, the solubility of these gases was investigated in BVO and it was demonstrated that although overall gas solubility is lower in BVO, like natural oils, the brominated vegetable oil exhibits higher $\mathrm{N}_{2} \mathrm{O}$ solubility. This was previously observed for lipidic ionic liquids, and indicates that a brominated version of the lipidic ionic liquid would also show the same trend.

With a more complete understanding of these phenomena, these characteristics could be exploited to produce compounds with specialized functions, particularly novel classes of lipidic ionic liquids. Oxidatively stable compounds with high viscosities could be considered for producing exceptionally stable lubricants derived from natural oils. Additionally, brominated alkyl side chains may provide a synthetic alternative to the inclusion of alkenyl side chains in lipidic ionic liquids, providing both melting point depression relative to the saturated chain and higher oxidative stability relative to unsaturated side chains. 


\section{Corresponding Author}

*Dr. Kevin N. West

Associate Professor

Department of Chemical \& Biomolecular Engineering

University of South Alabama

Mobile, AL 36688

kevinwest@southalabama.edu

251.460 .7563

\section{Acknowledgements}

KNW would like to thank American Chemical Service, Inc. for the donation of the BVO.

\section{Funding Sources}

This material is based upon work supported by the National Science Foundation under Grant Number 1133101. 


\section{REFERENCES}

[1] P. Bendig, L. Maier, W. Vetter, Brominated vegetable oil in soft drinks - an underrated source of human organobromine intake, Food Chemistry, 133 (2012) 678-682.

[2] C.V. Vorhees, R.E. Butcher, V. Wootten, R.L. Brunner, Behavioral and reproductive effects of chronic developmental exposure to brominated vegetable oil in rats, Teratology, 28 (1983) 309-318.

[3] S. Strom, Drink Ingredient Gets a Look, The New York Times, New York, New York, 2012.

[4] C. Choi, Coke, Pepsi dropping 'BVO' from all drinks, The Big Story, Associated Press, 2014.

[5] R. Nutzel, Process for brominating natural unsaturated oils, Rathor A.G., Switz.; Nutzel, Rainer . 1997, pp. 20 pp.

[6] S.M. Murray, R.A. O'Brien, K.M. Mattson, C. Ceccarelli, R.E. Sykora, K.N. West, J.H. Davis, Jr., The Fluid-Mosaic Model, Homeoviscous Adaptation, and Ionic Liquids: Dramatic Lowering of the Melting Point by Side-Chain Unsaturation, Angew. Chem., Int. Ed., 49 (2010) 2755-2758.

[7] A.E. Bradley, C. Hardacre, J.D. Holbrey, S. Johnston, S.E.J. McMath, M. Nieuwenhuyzen, Small-Angle X-ray Scattering Studies of Liquid Crystalline 1-Alkyl-3-methylimidazolium Salts, Chemistry of Materials, 14 (2002) 629-635.

[8] S.V. Dzyuba, R.A. Bartsch, Influence of structural variations in 1-alkyl(aralkyl)-3methylimidazolium hexafluorophosphates and bis(trifluoromethyl-sulfonyl)imides on physical properties of the ionic liquids, ChemPhysChem, 3 (2002) 161-166.

[9] C.M. Gordon, J.D. Holbrey, A.R. Kennedy, K.R. Seddon, Ionic liquid crystals: hexafluorophosphate salts, Journal of Materials Chemistry, 8 (1998) 2627-2636.

[10] J.D. Holbrey, K.R. Seddon, The phase behaviour of 1-alkyl-3-methylimidazolium tetrafluoroborates; ionic liquids and ionic liquid crystals, Journal of the Chemical Society, Dalton Transactions: Inorganic Chemistry, DOI (1999) 2133-2140.

[11] I. Lopez-Martin, E. Burello, P.N. Davey, K.R. Seddon, G. Rothenberg, Anion and cation effects on imidazolium salt melting points: a descriptor modelling study, ChemPhysChem, 8 (2007) 690-695.

[12] M.-L. Kwan, A. Mirjafari, J.R. McCabe, R.A. O'Brien, D.F.I.V. Essi, L. Baum, K.N. West, J.H. Davis, Jr., Synthesis and thermophysical properties of ionic liquids: cyclopropyl moieties versus olefins as Tm-reducing elements in lipid-inspired ionic liquids, Tetrahedron Lett., 54 (2013) 12-14.

[13] A. Mirjafari, S.M. Murray, R.A. O'Brien, A.C. Stenson, K.N. West, J.H. Davis, Structurebased tuning of $\mathrm{Tm}$ in lipid-like ionic liquids. Insights from $\mathrm{Tf} 2 \mathrm{~N}$ - salts of gene transfection agents, Chem. Commun. (Cambridge, U. K.), 48 (2012) 7522-7524.

[14] R.A. O’Brien, A. Mirjafari, K.M. Mattson, S.M. Murray, N. Mobarrez, E.A. Salter, A. Wierzbicki, J.H. Davis, K.N. West, The Effect of the Sulfur Position on the Melting Points of Lipidic 1-Methyl-3-Thiaalkylimidazolium Ionic Liquids, The Journal of Physical Chemistry B, 118 (2014) 10232-10239.

[15] K.N. West, B.D. Green, R.A. O’Brien, J.H. Davis, Binary Phase Behavior of Lipidic Ionic Liquids, AIChE Annual Meeting, Atlanta, GA, 2014.

[16] J.L. Anthony, J.L. Anderson, E.J. Maginn, J.F. Brennecke, Anion Effects on Gas Solubility in Ionic Liquids, J. Phys. Chem. B, 109 (2005) 6366-6374.

[17] P. Navia, J. Troncoso, L. Romani, Isobaric Thermal Expansivity for Nonpolar Compounds, J. Chem. Eng. Data, 55 (2010) 2173-2179. 
[18] G.S. Fulcher, Analysis of recent measurements of the viscoslity of glasses, J. Am. Ceram. Soc., 8 (1925) 339-355.

[19] G. Tammann, W. Hesse, Die Abhangigkeit der Viskositat von der Temperatur bei unterkuhlten flussigkeiten (The dependence of the viscosity on temperature for super-cooled liquids), Z. Anorg. Allg. Chem., 156 (1926).

[20] H. Vogel, Das Temperaturabhangigkeitgesetz der Viskositat von Flussigkeiten (The temperature dependence of the viscosity of liquids), Phys. Z., 22 (1921) 645-646.

[21] B. Esteban, J.-R. Riba, G. Baquero, A. Rius, R. Puig, Temperature dependence of density and viscosity of vegetable oils, Biomass Bioenergy, 42 (2012) 164-171.

[22] O.O. Fasina, Z. Colley, Viscosity and Specific Heat of Vegetable Oils as a Function of Temperature: $35^{\circ} \mathrm{C}$ to $180^{\circ} \mathrm{C}$, International Journal of Food Properties, 11 (2008) 738-746.

[23] C.L. Yaws, Yaws' Handbook of Thermodynamic and Physical Properties of Chemical Compounds, Knovel.

[24] I.R. Krichevskii, Y.S. Kazarnovskii, Thermodynamic calculations of solubilities of nitrogen and hydrogen in water at high pressures, J. Am. Chem. Soc., 57 (1935) 2168-2171.

[25] E.W. Lemmon, H.L. Huber, M.O. McLinden, NIST Standard Reference Database 23: Reference Fluid Thermodynamic and Transport Properties-REFPROP, National Institute of Standards and Technology, Standard Reference Data Program, Gaithersburg, 2013.

[26] E.W. Lemmon, R. Span, Short Fundamental Equations of State for 20 Industrial Fluids, J. Chem. Eng. Data, 51 (2006) 785-850.

[27] R. Span, W. Wagner, A new equation of state for carbon dioxide covering the fluid region from the triple-point temperature to $1100 \mathrm{~K}$ at pressures up to $800 \mathrm{MPa}$, J. Phys. Chem. Ref. Data, 25 (1996) 1509-1596.

[28] A. Yokozeki, M.B. Shiflett, The solubility of $\mathrm{CO} 2$ and $\mathrm{N} 2 \mathrm{O}$ in olive oil, Fluid Phase Equilib., 305 (2011) 127-131. 